\title{
LEARNING AND PRACTISING SUPPLY CHAIN MANAGEMENT STRATEGIES FROM A BUSINESS SIMULATION GAME: A COMPREHENSIVE SUPPLY CHAIN SIMULATION
}

\author{
Li Zhou \\ Ying Xie \\ Nigel Wild \\ Business School, University of Greenwich \\ Park Row, Greenwich, SE10 9LS \\ London, UK
}

\author{
Charles Hunt
}

Hunt Research and Development Ltd

68, The Circle, Queen Elizabeth Street

London, UK

\begin{abstract}
An Internet based supply chain simulation game (ISCS) is introduced and demonstrated in this paper. Different from other games and extended from the Beer Game, a comprehensive set of supply chain (SC) management strategies can be tested in the game, and these strategies can be evaluated and appraised based on the built-in Management Information System (MIS). The key functionalities of ISCS are designed to increase players' SC awareness, facilitate understanding on various SC strategies and challenges, foster collaboration between partners, and improve problem solving skills. It is concluded that an ISCS can be used as an efficient and effective teaching tool as well as a research tool in operations research and management science. Problems and obstacles have been observed while engaging in the SC business scenario game. The actions proposed and implemented to solve these problems have resulted in improved SC performance.
\end{abstract}

\section{INTRODUCTION}

Simulation games, either in the manual participative or computer-based form, have become popular teaching tools for active learning in business education. Other hands-on exercises like work design exercises, \& process flow design exercises are also widely adopted in education. These games and hands-on exercises can greatly facilitate the students' learning concerning practical issues and approaches.

Since the Beer Game was developed in the 1960s at the Massachusetts Institute of Technology's (MIT) Sloan School of Management (Sterman 1989, Senge 1990), it has attracted much attention from both Supply Chain Management (SCM) management practitioners and academics. The Beer Game has been used as a powerful tool to demonstrate the bullwhip effect (Forrester 1961; Lee, Padmanabhan, and Whang 1997a, 1997b). Goodwin and Franklin
(1994) used the Beer Game to teach systems thinking as it can dramatically demonstrate how powerful systems are and how important it is for managers to understand them. $\mathrm{Wu}$ and Katok (2006) investigated the effect of learning and communication on the bullwhip effect in SC by playing the Beer Game. It was found that training improved individual's knowledge but not the SC chain performance unless communication between partners was allowed and knowledge shared.

Other problems were also discovered within the game (Holweg and Bicheno 2002), i.e. the Beer Game is a pure retail distribution game without taking product conversion into account; it does not have the characteristics of set up times, process reliability and quality problems found in the SC (Taylor 1999); it does not take capacity issues into account; it can not model the service SC as the service SC does not have inventory stocks (Anderson and Morrice 2000). Therefore, Beer Game has been extended in different ways.

Sparling (2002) presented a four-phase strategy for teaching SCM topics around the Beer Game, and it leads students from an introduction to the problems of SCM (phase 1) through to solving those problems by cooperative planning, forecasting and inventory management (phases 2-4). Phases 2-4 are designed around a computerized version and supporting spreadsheets. A participative simulation model "Lean Leap Logistics Game" was built on a series of mapping activity in (Holweg and Bicheno 2002), and took into consideration of set up times, process reliability, quality problem as well as capacity issues. The game was used to demonstrate supply chain dynamics and to model possible improvements to an entire supply chain, e.g., collaboration between companies, synchronization between supply and demand. Anderson and Morrice (2000) developed "Mortgage Service Game" to model the service supply chain where finished goods inventory was not an option and capacity adjustment was used for order backlog. Kimbrough, Wu and Zhong (2002) investigated whether 
artificial agents do better than humans when playing the MIT Beer Game, in terms of policies that are used to make orders and mitigate the bullwhip effect. They have found that artificial agents implemented using Genetic Algorithm is capable of playing the Beer Game effectively.

In this paper, the Beer Game is redesigned to be an Internet based SC challenge Simulation game (ISCS) by Nigel Wild and Charles Hunt technically (www.supplychaingame.com). With a Management Information System (MIS) built in to support decision making. The key features of the game are: 1) ISCS is an online multi user information system which links every player together using Internet technology; 2) a set of comprehensive SCM strategies can be tested in the game; 3) a "consultant" role is designed into the game in order to provide general guidance; 4) challenges faced in implementing the strategies and approaches for meeting these challenges are identified; 5) the SC management strategies can be evaluated and appraised for differing supply chain scenario's based on the reports generated by the MIS system, 6) the simulated supply chain can be remodeled during the simulation. ISCS has been successfully running at postgraduate level in the University of Greenwich (UoG) since it was first launched in 2005, and it is proved to be an efficient and effective teaching and assessment tool to increase SC awareness, facilitate understanding on various SC strategies and challenges, foster collaboration between partners, and improve problem solving skills. Moreover, there is possibility to explore ISCS to be a research tool in operations research and management science. This motives us to disseminate the game and teaching experiences, as well as unscramble students learning process and outcomes.

The paper is organized as following. Section 2 describes the ISCS and provides details of how to engage in the supply chain challenge. Section 3 is our observation of students' learning experiences. Section 4 proposed actions against problems. Section 5 concludes.

\section{DESCRIPTION OF THE SC CHALLENGE BUSINESS SIMULATION}

The ISCS is designed to facilitate learning in the following areas of SCM:

- Order fulfillment cycles and customer service;

- Purchasing;

- Inventory and production planning and control;

- Transport planning \& scheduling;

- Warehouse management;

- Forecasting Systems;

- Supply Network Design;

- The Value of Information Sharing;

- Collaboration;

- Innovation;

- Leadership skills \& team building.
The simulation's complexity comes from the capacity constraints that limit the flow of materials from production to customer. Every customer order has a delivery date specified and the "players" must aim to deliver their orders to the customer on time. Deliveries made to early or too late are met with a financial penalty.

The unique attributes are: (1) ISCS offers incredible flexibility. The simulated SC can be instantly re-modeled during the simulation. For example storage/production capacities can be upgraded, warehouses can modify for greater efficiency. (2)The course content is designed to fit into the learning outcomes.

As it is shown in Figure 1, the ISCS contains five modules; customer, purchasing and fulfillment, production planning and production, regional distribution centre (RDC) and local distribution centre (LDC), and two third party logistics (3PL) with specific expertise respectively. The game needs a minimum of seven players and at least one member should be assigned to each functional unit such as production or 3PL etc. The role of the SC leader is to monitor overall performance, communicate with the team members, adjust SC strategy, and consult with the consultant. The consultant is usually played by a lecturer/tutor. He/she acts as an advisor to participants in the simulation. The role is to be reactive not proactive to players questions. He/she also "controls" the time periods within the simulation and administrates the software. The software represents to some degree an ERP system and records the activities of the "players". Students are encouraged to switch roles in each business quarter - however, the customer and consultant roles are kept as permanent roles through out the simulation. Students have a chance to get familiar with all functions in the simulation game.

The software system comes in two parts; an Internet based server records all simulation activity and a downloadable "client" software package provides the MIS and ERP functions to the participants. The ERP tracks the game processes and records all activity. Fines are automatically calculated, which alleviates the cumbersome issue of book keeping by the players and mitigates against cheating (creative book keeping) and mistakes (misunderstanding of the rules) which would obviously distort the result. The MIS generates a comprehensive set of reports including cash balance sheet, capacity usage, order history, purchasing and sales transactions, production data, financial penalties and global benchmarking statistics. All of this information is based upon the participants' activities. At the close of the simulation a "score" is given to the respective teams.

The ISCS needs at least one day to run. Ideally, two or three days are better for students to grasp all SCM related concepts and apply them to problem solving. The story of ISCS starts as an ongoing situation with the team taking over a working SC operation, with purchased stock, manufactured products coming off the production line, existing 


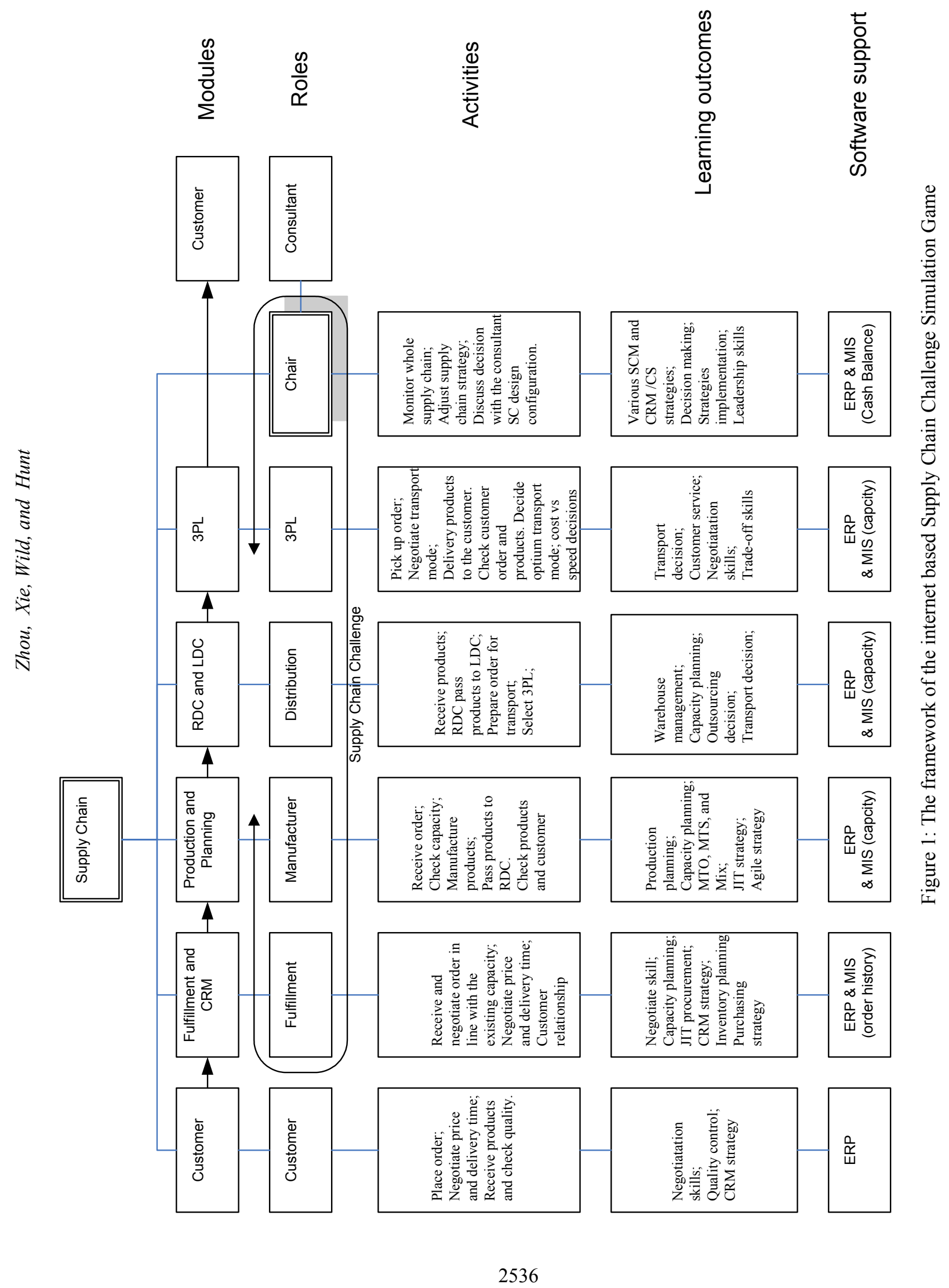


stock levels in warehouses, and customer orders moving in the pipeline via 3PL's. The existing organizational structure is shown as Figure 2.

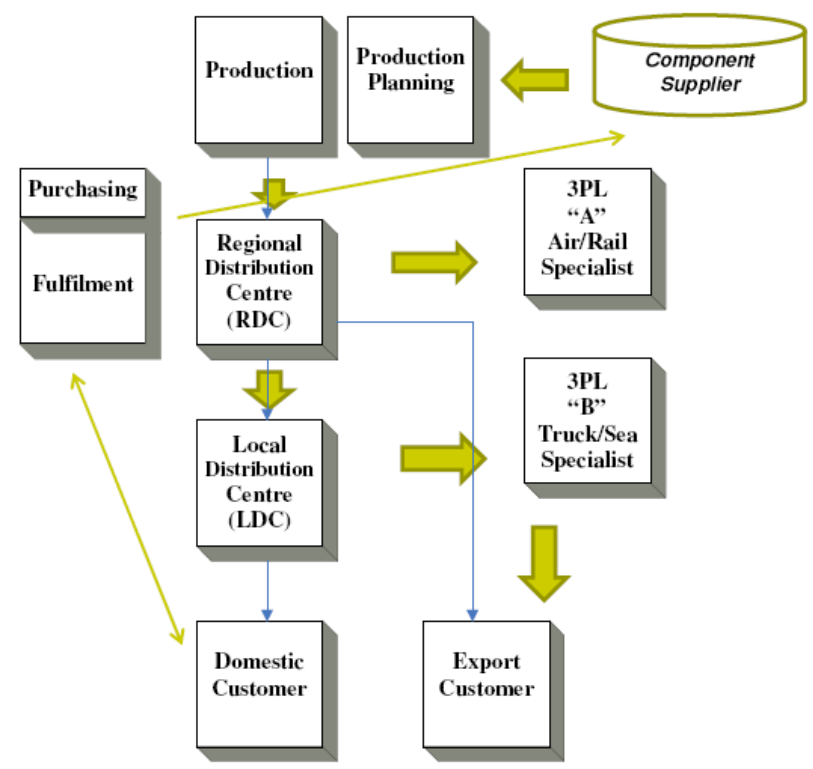

Figure 2: ISCS organizational structure

There are five types of products in the SC. The product with the lowest price and highest demand implies the possibility of adopting a lean strategy whilst the most expensive product requires advanced technology and high flexibility in terms of design features and delivery to the customer where an agile strategy is expected to be implemented.

A set of SCM strategies can be tested in the game: Customer relationship management (CRM) and the customer service dimension, capacity planning and inventory management, total quality management (TQM), production planning, purchasing strategies, logistics performance strategies, forecasting strategies, lean strategy, agile strategy, SC collaboration \& integration strategies. Before running the game, strategies may be reviewed to provide a theoretical background to students, and the game rules are also introduced. In particular the fine system is emphasized including capacity fines, early or late delivery fines and defective product fines. The teams are charged for making decisions that would incur additional costs, and capacity breaking is fined. This is calculated. Using a technology such as RFID would enable the software to follow the physical flow of material and could detect stock movement errors.

The process mirrors a real SC, and sounds simple, but there are lots of decisions to be made. The unit time period of running the game is defined as "run", which takes 10 unit lead times, i.e., 1) customer releasing orders, 2) purchasing product component parts 3) production planning, 4) manufacturing, 5) transporting to $\mathrm{RDC}, 6) \mathrm{RDC}$ throughput 7) RDC to LDC, 8) LDC throughput 9) 3PL picking up orders from RDC (international) LDC (Domestic), and 10) delivering orders to customers.

The ISCS takes place over 4 business quarters, and each quarter is composed of a time period, for example one hour, where a number of runs can be determined, either by the business simulation controller, or by the players requests to increase runs within a quarter. The controller does set a minimum period per run using the flexible preset timing period built into the simulation. i.e. 20 minutes per run. The minimum time period may be decreased each quarter (optional) to facilitate faster decision making as the scenario progresses. After each business quarter a management review takes place: the SCM strategies are evaluated and appraised based on the reports generated in the MIS system, and a range of discussion topics are provided (see example in Appendix). Students are expected to learn from their mistakes, and the SC Leader can ask for advice from the consultant.

\section{OBSERVATON OF STUDENTS' LEARNING EXPERIENCE}

We discover the obstacles and problems from the observation of students' playing the game.

\subsection{Team Work and inter-SC Communication}

Team members tended to focus on their assigned functional unit and would neglected communication with other members. All they have to do is to pass information regarding the order's progress upstream or/and deliver the products to downstream SC neighbors on time. Theoretically, they "perfectly" understand the " $7 \mathrm{R}$ " principles of logistics, i.e. Right product of Right quality and Right quantity delivered to the Right customer in Right time and Right place with the Right cost. But the fact was that the attention was paid only to "right quantity" and "right time". They lack the awareness of lead time issue in SC, which means they only check their existing inventory level and forget to chase WIP orders until they are out of stock or face the imminent prospect of late delivery.

The lack of communication within the team is also embodied through the identification of problems, mistakes or other issues, caused in one business unit do not get communicated to other units in time, which causes the SC become highly disordered.

\subsection{Customer Relationship Management (CRM) and Customer Service (CS)}

The term "customer" was incorrectly defined by the team. They only treated the external customer as a "customer". Where as any "downstream unit" should be considered a 
customer, who should be "maintained" with information and appropriate service levels. Almost all the players thought it should be the Fulfillment department's job to communicate with the external customer.

The external customers got the cold shoulder. They complained that the fulfillment department seemed to only care about how many orders they could receive regardless how the customers felt. As a result, the customer became tough and even uncooperative when negotiate order volumes, prices and delivery times.

Nevertheless, some kind of internal CRM adjustment took place after reviewing quarter I performance. The internal SC relationships subsequently improved. In solving internal CRM issues, the SC leader focused the attention of each functional unit's performance, so that any operational issue arising from a particular unit was notified to the entire SC so that other functional units could adjust their policy in time. In terms of external CRM, the SC leader would specify one member to work closer with the customer to discuss customer special needs and then report directly to the leader. From quarter II, the ISCS process was gradually becoming more refined.

With the benefit of good CRM practice, students finally realized that the customers were willing to provide historical demand data and share the demand trends with them, which enabled more accurate forecasting within the SC.

\subsection{Capacity Planning and Inventory Management}

Capacity planning turned out to be one of most difficult tasks for students. No one student can cope with capacity constraint in any functional unit, which resulted in financial penalties and SC performance deteriorating.

The failure in capacity planning resulted from a lack of regular capacity checks and poor demand forecasting.

In terms of inventory management, unsurprisingly both overstocking and stock out situations occurred in turn. More interesting, there is no clear signal to show that the stock level in each department is affected by upstream or downstream decision. Initially, students made inventory decision based on the "feeling" rather than "forecasting" demand.

The MIS system reports help students to analyze their capacity and inventory situation, especially, when they are able to integrate customer information such as order history and demand trends. A Lean strategy was soon adopted with the purpose of minimising inventory and maintaining customer service levels.

\subsection{Quality Control}

Quality control is twofold: firstly; product quality and secondly; service quality. Nevertheless, players' engaging in the simulation, had not given product quality control enough attention until customers refused to accept defective products. TQM was not implemented throughout the SC. Although the product quality control in the game is relatively simple as there are only five products, and it is relative easy to avoid such problems if quality controllers function is assigned to the production unit which is the earliest stage the product quality problem could emerge.

The control of service quality was rather jumbled in terms of right product, right quantity and right time, which is one of common reasons for incurring a fine. A cause of this problem is the lack of coordination and communication between each functional unit.

\subsection{Production Planning and Manufacturing}

As most students have no production engineering background, it could be predictable and understandable that very few students can schedule production by establishing a realistic master production schedule from which joborder sequences are derived. Students are expected to make production plans based on analyzing available resources; capacity, raw materials, existing inventory levels, WIP, and staff availability. These factors are weighed against market demand forecasts, which may be restrictive when demand is not solicited from customers.

In most case, the production unit unconsciously adopts a push strategy instead of an expected pull strategy. Therefore, an order backlog builds which results in financial penalties, increasing costs due to higher inventory levels and capacity breaking. This situation is slightly alleviated after quarter III as the SC reacts to an over stocked inventory and adjusts production strategy due to SC throughout lead time.

\subsection{Transport Intermodal Strategies}

Due to the nature of the products, there are only four transport modes in the game; air, rail, truck and sea. The students failed to make optimal use of the transportation modes; there was a lack of integration between RDC and 3PL's for scheduling and costs. There were no attempts to create cross-modal mergers or alliances which might have sought to trade of speed against cost, in order to increase total transport efficiency.

\subsection{Performance Measurement}

Theoretically, students understand the various SC performance measurements such as cost, speed, quality etc. However, in practice, the students' actions are not consistent with their targets. The targets are set to minimise total cost whilst in practice all their efforts were made for quick response or delivery on time. 
In fact, what is expected is that lean strategies should be adopted to reduce total cost, whilst agile strategies are adopted for quick response.

\section{ACTIONS AGAINST PROBLEMS}

After engaging in the SC Challenge for 4 business quarters, students come to grasp the array of SC problems. The following summarizes their understanding and most probable indicative behaviour given an opportunity to partake in the simulation again.

\subsection{Collaboration and Integration with Customers and Suppliers}

The need to seek to engage customers in a process of consultation and participation, through both formal and informal channels as described in theory by pinto (2007). Students plan to invite customers to express their view on service operations, such as:

- Checks on quality product and processes to gain trust and loyalty, to improve customer satisfaction/retention.

- Propose better delivery methods by integrating with 3PL's. 3PL's to check with customers if delivery planning is geared to customer requirements.

- Customers become part of the decision planning by encouraging them to assist in demand forecasting.

- Encouraging customers to suggest enhancements to the range of services, raging from quality, delivery time, and prices and after sales services, as described by McKenna (1991).

- A R\&D department will be established which will monitor the order fulfillment and production planning processes which directly deal with customers. The R\&D department should supervise each development stages of production, such as, aspects of customer relations, price negotiation, feedback from customers on our service failure and service recovery, planning process, quality and forecasting, etc.

\subsection{Inventory Control and Purchasing Strategy with Suppliers}

A Vendor Managed Inventory (VMI) may be adopted. The main purpose is to reduce the safety stock and overall inventory level. Applying VMI should create greater visibility throughout the SC systems. There should be direct collaboration between production planning and suppliers. SC planners should be able to schedule production and distribution throughput against the existing stocks levels. Such integration should facilitate smoother movements of mate- rials \& efficient utilization of space. A lean process that would allow an estimation of the supplies of materials according to the job order, resulting in reduced waste, and holding materials with the suppliers until needed - and at the same time the requirement for safety stock would be considerably reduced.

\subsection{Transport Intermodal Strategies}

To achieve a cost effective and time efficient delivery, time process mapping should be undertaken. Some decisions may take place based on the marketing environment and current SC performance, such as:

- RDC may be operated according to the principles of Agile Strategy to reduce the lead time gap and speed up delivery time.

- Set up a decoupling point to meet customer orders utilizing lean mapping techniques.

- Convert the RDC to a cross docking operation in order to reduces handling and storage of inventory and be able to deliver finished goods directly to the customer to reduce the lead- time.

- LDC outsourced or closed down, a trade-off between speed and cost objectives.

\subsection{Performance Measurement Strategy}

Develop more workable and realistic performance measurement metrics, which should be established and evaluated. These may include methods such as benchmarking (Bowersox, Closs, and Cooper 2007), customer orientated metrics, internal dimension metrics, and financial dimension (Cohen and Roussel 2005).

\subsection{SC Leadership}

SC leaders are very important and should be capable of:

- Leveraging SC innovations for sustainable competitive advantage;

- Responding to competitive challenges throughout the value chain;

- Build SC partnerships that manage all the SC elements for the benefit of each partner;

- Motivate others by addressing individual and organizational behaviour issues that pose barriers to SC performance;

- Attend to process details and operational execution, while creating strategic plans;

- Understand the role of information technology in the SC (Corsi et al. 2006)

\subsection{The Need for Emergency Flexible Structure}

Emergency flexible operations are pre-planned strategies to resolve logistical failures. A typical emergency occurs 
when an assigned shipping facility is out of stock or for some other reason cannot complete a customer's order. For example, in one SC Challenge scenario during the last run of the third business quarter one of the teams goals was to clear out all the warehouse stock, because the stock level was very high, the team was increasing costs reflecting in a poor financial performance. In order to solve that problem, the team members created an emergency flexible plan. The plan was solely focusing on clearing out all the stock by using the 3PL to work effectively and efficiently. This strategy helped the team to reduce costs by reducing the storage in the warehouse. This resulted in an improved financial performance and increased profits. The use of emergency flexible operation procedures is typically based on the importance of the specific customer requirements or the critical nature of the product being ordered.

\section{CONCLUSION}

This paper introduced an internet-based SC challenge business scenario simulation. The purpose of the SC simulation is to facilitate learning in SCM strategies. The obstacles and problems in engaging in the simulation have been identified from our observations, and further actions proposed to improve overall SC performance have been taken by the students. MIS reports demonstrate that improved SC performance has been achieved both from a financial aspect, and a customer service level perspective. The detailed reports can be provided by the authors upon request.

For further research, it would be worthwhile to diagnose the students' performance in more detail.

\section{ACKNOWLEDGEMENTS}

The authors would like to thank Yang Yang, Catherine Ahiekpor, Adedayo Akinsanya and other members of MA E-logistics and MSc Project Management for Logistics for sharing their learning experiences with us.

\section{APPENDICES}

\section{Business quarter I: Discussion Topics}

- Customer relationship management and the customer service dimension

$\circ$ What issues are arising in your dealing with your customer?

- What is becoming more important the price you charge the customer or ability to meet delivery time?

- What steps are you taking to ensure you measure your ability to meet customer delivery times?

- Transport Intermodal strategies
- What processes have you set up to help select your transportation choices between speed and cost?

- Purchasing Strategies

$\circ$ What measures are you adopting to ensure available inventory for WIP in the factory?

- Can operate in complex and unpredictable and/or logistics and supply chain context's, and has an overview of logistics and supply chain issues governing good practice

$\circ$ What actions are you taking to resolve issues arising in the Supply Chain concerning; (a) Complexity? (b) Unpredictability?

\section{Business quarter II: Discussion Topics}

- Global logistics strategies

- How does your domestic strategy differ from your International strategy?

- Logistics Performance strategies

○ What measures are you taking to monitor your performance?

- If you can't measure what you are doing how will you improve it?

- Forecasting strategies

- Are you able to demonstrate how you are tackling demand forecasting.

- Evaluate and appraise Logistics and operations measures to improve efficiency and effectiveness in the supply chain

- What are the evaluation techniques you are/ or should adopt to improve upon your efficiency in the supply chain?

- Critically understand the key elements of the information systems that link organizations and supply chain networks together

$\circ$ What are the advantages that the "SC Challenges" information system may afford you in improving efficiency?

\section{Business quarter III: Discussion Topics}

- Lean Supply Chain Strategies, methods and techniques

○ How could you (or are you) applying lean mapping techniques and strategies through your supply chain?

- Determine the benefits you expect to realise from a Lean approach?

- What are the major challenges you are facing in implementing integrated supply chain management strategies?

- Evaluate the benefits of seeking to introduce SC management improvement methods to enhance your performance in the SC Challenge. 
Business quarter IV: Discussion Topics

- Agile Supply Chain Strategies, methods and techniques

- Where do you believe the P time and D time decoupling points are?

- Calculate the lead time gap.

- Supply chain collaboration \& integration strategies

- Evaluate your integration \& collaboration strategies.

- Where can you add value in terms of efficiency \& effectiveness through the adoption of integration and collaboration strategies?

- Appraise, and evaluate the relevance of particular SCM strategies for differing supply chain scenario's.

- Explain your overall strategy to maximise group efforts to optimise supply chain efficiency in order to maximise customer satisfaction.

\section{REFERENCES}

Anderson, E. G., and D. J. Morrice. 2000. A Simulation Game for Service-Oriented Supply Chain Management: Does Information Sharing Help Managers with Service Capacity Decisions The Journal of Production and Operations Management 9(1): 40-55.

Bowersox, J. B., D. Closs, and M. Cooper. 2007. Supply chain logistics management. Second edition, McGrawHill/Irwin Companies Inc., New York, Chap. 6, pp. 130-132

Cohen, S., and J. Roussel. 2005. Strategic supply chain management - The five disciplines for top performance. The McGraw-Hill Companies, Inc. Chap. 2, pp. $49-100$.

Corsi, T. M., S. Boyson, A. Verbraeck, S. P. Van Houten, C. Han, and J. R. Macdomald. 2006. The real time global supply chain game: New educational tool for developing supply chain management professionals. Transportation Journal 145(3): 61-73.

Forrester, J. W. 1961. Industrial Dynamics, MIT Press, Wiley, New York.

Goodwin, J. S., and S. G. Franklin. 1994. The beer distribution game: using simulation to teach systems thinking, Journal of Management 13(8): 7-15.

Holweg, M., and J. Bicheno. 2002. Supply chain simulation - a tool education, enhancement and endeavour, International Journal of Production Economics 78: $163-175$

Kimbrough, S. O., D .J. Wu and F. Zhong. 2002. Computers play the beer game: can artificial agents manage supply chains? Decision Support System 33: 323-333.
Lee, H. L., V. Padmanabhan, and S.Whang. 1997a. Information distortion in a supply chain: the bullwhip Effect," Management Science 43(4): 516-558.

Lee, H.L., V. Padmanabhan, and S. Whang. 1997b. The bullwhip effect in supply chains, Sloan Management Review 38 (3): 93-102.

McKenna, R. 1991. Relationship Marketing: Successful Strategies for the Age of the Customers. AddisonWesley.

Pinto, J. 2007. JimPinto.Com eNews, "collaboration strategies fuel growth \& success", Available via <http:// Www.jimpinto.com> [accessed December 27, 2007].

Senge, P. M. 1990. The Fifth Discipline, Doubleday, New York

Sparling, D. 2002. Simulations and supply chains: strategies for teaching supply chain management. Supply Chain Management: An International Journal 7(5): 334-342.

Sterman, J. D. 1989. Modeling managerial behavior: misperceptions of feedback in a dynamic decision making experiment," Management Science 35(3): 321-339.

Taylor, D. H. 1999. Measurement and analysis of demand amplification across the supply chain, International Journal of Logistics Management 10(2): 55-70.

Wu, D. Y., and E. Katok. 2006. Learning, communication, and the bullwhip effect, Journal of Operations Management 24(6): 839-850.

\section{AUTHOR BIOGRAPHIES}

LI ZHOU is a Senior Lecturer and the Postgraduate programme leader of MA E-logistics and SCM and MSc Project Management for Logistics. She received her BSc and MSc in Engineering and Ph.D in Management Science and Engineering. She has published over 30 refereed journal articles and conference papers. Her principal research interests lie in the field of operations management, specifically supply chain management and reverse logistics. The focus of her research has been on modeling and simulating supply chains and reverse logistics systems to analyze their economic performance. She acts as ad hoc referee for a number of international journals and the editorial board member for three new launched international journals.

YING XIE is a senior lecturer in the Department of System Management and Strategy at the University of Greenwich, UK. She received a master's degree in intelligence engineering from University of Liverpool, UK and a Ph.D. in supply chain management and control from Coventry University, UK. Her current research and teaching interests are in supply chain modeling and simulation, supply chain coordination, forecasting, optimization, multi-criteria decision making and artificial intelligence applications in op- 
erations research. She is a member of CILT (Chartered Institute of Logistics and Transport).

NIGEL R. WILD is a principle Lecturer and the Programme Area Director for the Department of Systems Management and Strategy at the University of Greenwich. He designed and implemented the Masters programme; MA e-logistics \& SCM, and has overseen the development of further degrees at Master's and Undergraduate level in SCM, logistics, purchasing \& transport. He received a BSc in Sociology \& a Postgraduate Dip. in Marketing from Kingston University, and MA Marketing and a Postgraduate dip. in Education from Greenwich University. He is a $\mathrm{PhD}$ candidate, researching; Barriers to collaboration between NGO's in humanitarian supply chains, with particular focus upon the development of a collaborative model for ethical procurement and purchasing for NGO aid organizations. He is co-author of the Supply Chain Challenge business scenario, and has experience in delivering business simulations. He has 20 years business experience as a director and corporate manager in global container shipping organizations. He has developed, owned and managed a series of SME's in the education and transport sectors. He is a FCILT, MIEX, FHEA.

CHARLES HUNT work as a consultant for Hunt Research \& Development Ltd in the field of business application software development. Over the last 18 years he has designed business solutions for businesses involved in purchasing, sales, distribution and manufacturing. He received a BSc in Computing Science from University of Greenwich as well as a masters degree in E Logistics \& Supply Chain Management. He is co-author of the Supply Chain Challenge business scenario and author of the Supply Chain Challenge system software. He has delivered a series of business simulations to post graduate business students. He is a member of the ACM (Association for Computing Machinery) and of the CILT. 